Bio-grafía. Escritos sobre la Biología y su Enseñanza. ISSN 2027-1034

Número Extraordinario. p.p. 192-200

Memorias del Primer encuentro ambiental Universidad, ambiente y sustentabilidad: experiencias y prácticas.

\title{
DERMATOFITOSIS, UNA PATOLOGÍA DERMATOLÓGICA QUE AFECTA A LOS HABITANTES DE LA CIÉNAGA DE LA VIRGEN
}

\author{
Rayo Daniel Felipe ${ }^{1}$, \\ Suesca Francy Liliana ${ }^{1}$, \\ Acevedo Iván Darío², \\ Cabarcas Andrés².
}

\section{Resumen}

La dermatofitosis es una enfermedad que afecta la piel, evidenciándose en el crecimiento de hongos en múltiples partes del cuerpo, generalmente las de mayor exposición. En la última década se ha encontrado que esta enfermedad se ha propagado en grandes proporciones, afectando principalmente los pobladores de la Ciénaga de la Virgen, por la elevada humedad y altas temperaturas. En ese contexto, esta investigación pretende identificar las propiedades antioxidantes y anti-micóticas que tiene la planta Cassia Fistula (Cañandonga) para prevenir la propagación del hongo en la piel de los habitantes de esta zona y/o mitigar los efectos producidos por los hongos dermatofitos en la dermis de los pacientes que se encuentren afectados.

Se realizó una extracción metanólica para el fruto de Cassia Fistula, planta que prolifera en la ciudad de Cartagena, y fue tratada junto con el grupo de investigación genoma de la Universidad del Sinú, posteriormente se aplicó el método de Bornträger a los extractos para comprobar la presencia de antioxidantes

\section{Palabras Claves:}

Tiña, Antraquinonas y naftoquinonas, Reacción de Borntrager.

\section{Abstract:}

Dermatophytosis is a disease that mainly affects the skin, evidenced in the growth of fungi in multiple parts of the body, which are mostly the

\footnotetext{
${ }^{1}$ Universidad Pedagógica Nacional, Estudiante de Licenciatura en Química, SISMA Semillero de investigación en salud y medio ambiente.wendany97@gmail.com, flsc13@hotmail.com.

${ }^{2}$ Universidad del Sinú, seccional Cartagena. Estudiante de medicina. idacemo2@gmail.com, andres_cabarccas95@hotmail.es.
} 
Bio-grafía. Escritos sobre la Biología y su Enseñanza. ISSN 2027-1034

Número Extraordinario. p.p. 192-200

Memorias del Primer encuentro ambiental Universidad, ambiente y sustentabilidad: experiencias y prácticas.

most exposed parts. In the last decade it has been found that this disease has been prolonged in a very wide speed, affecting mainly Ciénaga de la Virgen, since there proliferates the humidity and the high temperatures. This research aims to identify the antioxidant and antifungal properties of the Cassia Fistula plant to prevent the spread of the fungus on the skin of the inhabitants of this area.

A methanol extraction was carried out for the Cassia Fistula fruit, a plant that proliferates in the city of Cartagena, and was treated together with the genome research group of the University of Sinú, after which the method of Bornträger was applied to the extracts to verify the Presence of antioxidants

\section{Keywords:}

Ringworm, Anthraquinones and naphthoquinones, Borntrager reaction.

\section{OBJETIVOS}

Obtener el extracto de Cassia Fistula para probar, posteriormente, su acción antimicótica frente a dermatofitos.

\section{Objetivos específicos:}

- Obtener el extracto de Cassia Fistula, separando la Reina, como principio activo, mediante arrastre por polaridades.

- Realizar un análisis cualitativo, por el cual se pueda identificar la presencia de naftoquinonas y antraquinonas en cada uno de los extractos.

- Aportar bases teóricas por medio de los análisis realizados, que permitan sustentar un tratamiento frente a dermatofitos.

- Socializar de manera didáctica los resultados obtenidos puntualizando en la incidencia de procesos experimentales e investigativos para el afianzamiento de conceptos de química analítica. 
Bio-grafía. Escritos sobre la Biología y su Enseñanza. ISSN 2027-1034

Número Extraordinario. p.p. 192-200

Memorias del Primer encuentro ambiental Universidad, ambiente y sustentabilidad: experiencias y prácticas.

\section{MARCO TEÓRICO}

Para Restrepo y colaboradores (2007) los dermatofitos constituyen una de las lesiones cutáneas infecciosas más frecuentes, relacionadas con casos aislados, brotes y epidemias. Son micosis de individuos inmunocompetentes, que cuando se encuentran en condiciones de inmunosupresión pueden revestir mayor extensión, polimorfismo, cronicidad, y menos respuesta a la terapia. Los dermatofitos rara vez producen micosis profundas, localizadas a la dermis, tejido celular subcutáneo y rara vez a órganos profundos; estas formas se relacionan con terapia o enfermedades inmunosupresoras.

Según, Kelly (2012) son infecciones fúngicas superficiales y los dermatofitos son un gran grupo de hongos relacionados que pueden infectar la piel humana, cabello y uñas; que se encuentran en el suelo, en animales, y en los seres humanos. Estos hongos requieren queratina para el crecimiento $y$, por lo tanto, son incapaces de infectar las superficies mucosas; se encuentran en todo el mundo, aunque la especie específica, y la presentación clínica posterior, varía de región a región. Así mismo, su tratamiento presenta una variación, dependiendo de las condiciones de desarrollo de la patología pero en la mayoría de los casos se acude al suministro de fármacos antibióticos.

\section{Cassia Fistula}

$\rightarrow$ Nombre científico: Cassia fistula/ fistulae Labrum

$\rightarrow$ Nombre común: Caña fistula, lluvia de oro, cassia lluvia de oro, Cañandonga

$\rightarrow$ Familia: Fabaceae-Caesalpinaceae

$\rightarrow$ Origen: Exótica

Para Holdridge y colaboradores (1975) es una planta perteneciente al género Cassia ha demostrado actividad antifúngica, en nuestro contexto geográfico es común encontrar a la Cassia Fistula L. brindando la posibilidad de su aprovechamiento. La Cassia Fistula L. comúnmente conocida con los nombres de Caña Fistula, Lluvia de Oro o Cassia Lluvia de Oro; perteneciente a la Familia de las Fabaceae-Caesalpinaceae, originaria de la India que ha sido distribuida y cultivada en América Tropical y Subtropical en las regiones correspondientes al Pacífico. Se describe como un árbol mediano, de copa irregular, amplia y extendida, mostrando las ramas colgantes. Su fuste es ancho de hasta $45 \mathrm{~cm}$ de 
Bio-grafía. Escritos sobre la Biología y su Enseñanza. ISSN 2027-1034

Número Extraordinario. p.p. 192-200

Memorias del Primer encuentro ambiental Universidad, ambiente y sustentabilidad: experiencias y prácticas.

diámetro y recto. La corteza es lisa y gris en sus etapas tempranas, pero se torna escamosa y castaño rojizo cuando llega a estado adulto.

Sus flores son llamativas por su coloración amarilla o amarillo-dorado. Vistosas, fragantes, agrupadas en racimos terminales y colgantes de 25 a $75 \mathrm{~cm}$ de largo. Esta planta se encuentra abundantemente en Asia, América tropical y subtropical sobre todo en ciudades, por ser una planta floreciente (Angiospermas). "El árbol florece profusamente durante el verano, mientras que las vainas maduras son simplemente recogidas del suelo y desechadas como residuo" (Chewchinda, 2013)

\section{Antioxidantes:}

Según el portal antioxidantes "Los antioxidantes son aquellas moléculas que son capaces de retardar y/o prevenir la oxidación de otras moléculas." se encuentran de forma natural y en algunos alimentos; sirven para estabilizar radicales libres presentes en la comida, bloqueando de esta forma el daño oxidativo.

Otra propiedad importante, es que éstos presentan una vida media de microsegundos, característica que conlleva a una propagación muy veloz sobre moléculas aledañas y la generación de un mayor daño potencial. Según Coronado y colaboradores (2015) los radicales libres pueden actuar a nivel intracelular y otros en la membrana de las células, siempre en conjunto para proteger a los diferentes órganos y sistemas. 
Bio-grafía. Escritos sobre la Biología y su Enseñanza. ISSN 2027-1034

Número Extraordinario. p.p. 192-200

Memorias del Primer encuentro ambiental Universidad, ambiente y sustentabilidad: experiencias y prácticas.

\begin{tabular}{c}
\hline FIGURA 1 \\
Interacción entre radicales libres $\mathrm{y}$ antioxidantes \\
\hline
\end{tabular}

4

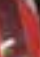
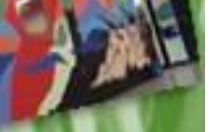

$\sqrt{2}$

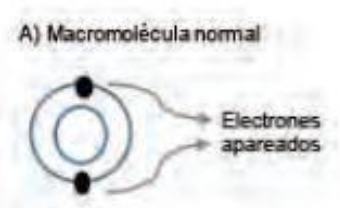

B) Macromolécula + oxígeno

se forma radical libre
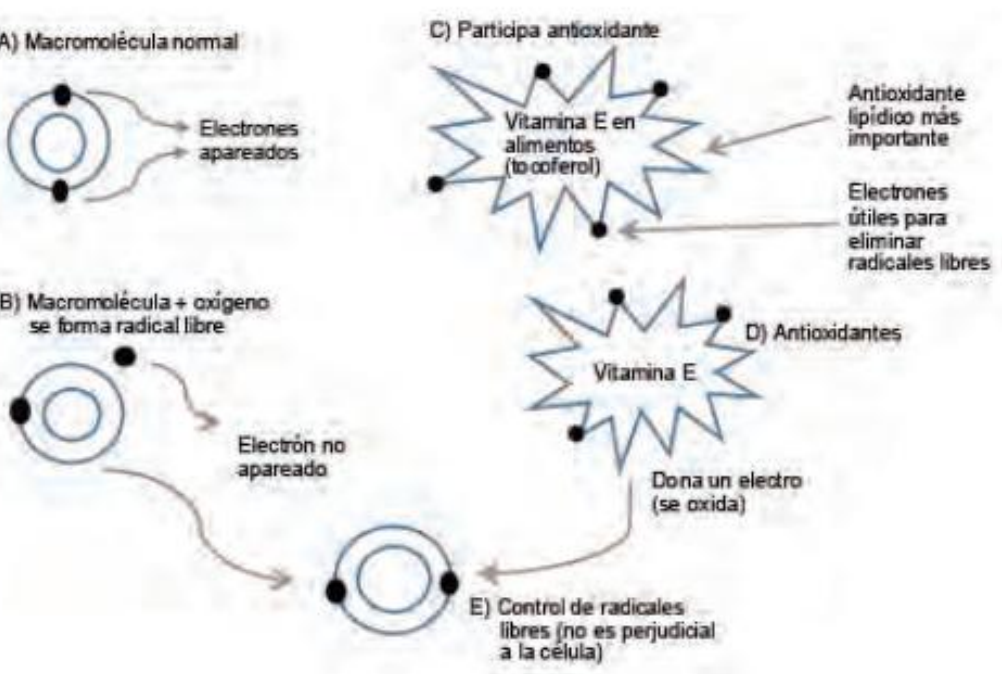

(figura 1). Fuente: Coronado, Vega, Rey, Vázquez, Claudia, (2015). Dos tipos de antioxidantes: perspectiva actual para la salud humana, tomada de: Portal Antioxidantes

\section{METODOLOGÍA}

1. Se recibió el material vegetal enviado desde Cartagena bajo el trabajo del semillero de investigación Genoma de la Universidad del Sinú. el día 11/Octubre/2016

2. Se colocaron a secar el día 15/Octubre/2016 hasta el día 25/Octubre/2016

3. El día $25 /$ Octubre/2016 se realizó la separación de la pulpa con la cáscara, se pusieron en frascos de ámbar y agregamos alcohol etílico.

4. Dejamos en reposo hasta el día 03/Noviembre/2016.

5. Se está realizando unos extractos de cloroformo de los frutos de Cassia fístula utilizando el método de difusión en disco de agar.

\section{Reacciones de Bornträger:}

Este método se utiliza para la identificación física de las antraquinonas, naftoquinonas y quinonas que se encuentren en un extracto vegetal, se 
Bio-grafía. Escritos sobre la Biología y su Enseñanza. ISSN 2027-1034

Número Extraordinario. p.p. 192-200

Memorias del Primer encuentro ambiental Universidad, ambiente y sustentabilidad: experiencias y prácticas.

realiza por medio de una solución de hidróxido de amonio, la cual nos va a dar una coloración roja si existe presencia de algunas estructuras mencionadas.

\section{Procedimiento:}

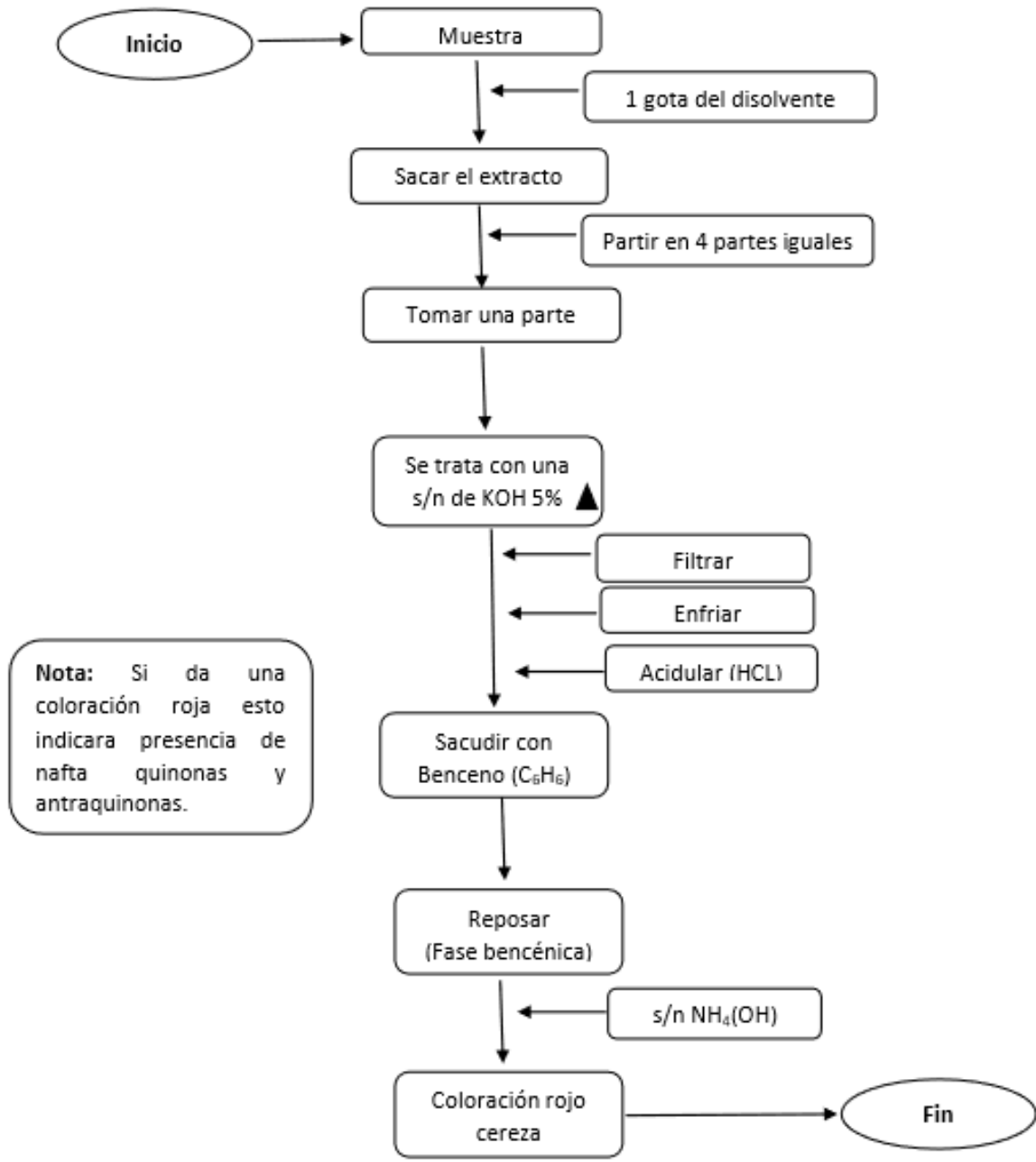

\section{RESULTADOS}

1. Se recibió el extracto de cañandonga (Cassia Fistula) por parte del semillero de investigación Genoma de la Universidad del Sinú, y se observaron sus propiedades organolépticas.

2. Se realizaron dos pruebas de Bornträger con los extractos de cloroformo y acetato de etilo. El resultado para dichas pruebas fue negativo ya que no se obtuvo la coloración esperada de rojo cereza, la cual permite identificar la presencia de antraquinonas en los extractos de la fruta. Debido a esto surgieron dos hipótesis, la primera 
Bio-grafía. Escritos sobre la Biología y su Enseñanza. ISSN 2027-1034

Número Extraordinario. p.p. 192-200

Memorias del Primer encuentro ambiental Universidad, ambiente y sustentabilidad: experiencias y prácticas.

que la coloración esperada correspondía a los reactivos y las condiciones del protocolo aplicado pero no necesariamente a las que estábamos desarrollando en nuestro caso y la segunda, que los extractos en estudio, habían sufrido una degradación debido a las condiciones de almacenamiento, transporte, tiempo de conservación, etc. Así que se propuso lo siguiente:

2.1. Realizar una estandarización de la prueba de Bornträger sobre frutos o especies cuyo contenido de antraquinonas fuese alto; posteriormente, tomar las cantidades empleadas y las coloraciones obtenidas para trabajar con Cañandonga. Es así como se eligió Aloe Vera debido a que la literatura reporta un alto contenido de antraquinonas en su estructura. (Vega, 2005) Se aplicó el protocolo para Bornträger y se sistematizaron los datos obtenidos.

2.2 Paralelo a ello, se procede a la obtención de un nuevo extracto de Cassia Fistula y la subsecuente separación por polaridades. Se proyecta aplicar la prueba, ya estandarizada, sobre las fases de acetato de etilo y cloroformo.

\section{CONCLUSIONES}

La dermatofitosis se presenta como una patología de la piel que afecta a los habitantes de la ciénaga de la virgen (Cartagena). Debido a sus condiciones geográficas, climáticas y socioeconómicas, se trata de un cuadro cuyo diagnóstico y tratamiento es complejo debido a que los antibióticos que normalmente se usan para su control no son suficientes para sanar al individuo de esta afectación ó éste último no cuenta con los recursos económicos que le permitan sostener las indicaciones médicas. Por ello se hace necesario acudir a tratamientos alternativos que puedan resolver esta situación de la mejor manera posible.

En ese contexto emerge el interés de trabajar con Cassia Fistula una especie vegetal de fácil adquisición en la ciudad de Cartagena y sus alrededores cuyo fruto, por su olor característico es frecuentemente tratado como un residuo orgánico; sin aprovechar las propiedades antimicóticas, antioxidantes y antiinflamatorias que posee (Nasir, 2005). Se espera que un extracto de ésta especie vegetal pueda actuar frente a los hongos dermatofitos impidiendo su proliferación e inclusive llegando a erradicarlos. Para lograrlo se debe pasar por una serie de procedimientos 
Bio-grafía. Escritos sobre la Biología y su Enseñanza. ISSN 2027-1034

Número Extraordinario. p.p. 192-200

Memorias del Primer encuentro ambiental Universidad, ambiente y sustentabilidad: experiencias y prácticas.

que implican la extracción de la materia vegetal, su separación por polaridades y la realización de la prueba bonträger para verificar el contenido de antraquinonas. Actualmente, se está aplicando un piloto de dicha prueba que ha ido progresando en términos de su estandarización.

Por otro lado, las bases teóricas recopiladas hasta el momento, han ayudado a sustentar el desarrollo de las prácticas para la mejora del tratamiento de la dermatofitosis. 
Bio-grafía. Escritos sobre la Biología y su Enseñanza. ISSN 2027-1034

Número Extraordinario. p.p. 192-200

Memorias del Primer encuentro ambiental Universidad, ambiente y sustentabilidad: experiencias y prácticas.

\section{REFERENCIAS BIBLIOGRÁFICAS}

Chewchinda, S, Wuthi-udomlert, M, Gritsanapan, W. (2013). Quantitative Analysis of Rhein and Antidermatophytic Activity of Cassia Fistula Pod Pulp Extracts of Various Storage Conditions, HPLC, BioMed research international.

Geilfus F. (1989). El árbol: al servicio del agricultor. Manual de agroforestería para el desarrollo rural. Principios y técnicas. Santo Domingo.

Holdridge LR, A LJP (1975). Árboles de Costa Rica: Centro Científico Tropical San José, Costa Rica.

Kelly BP. (2012), Superficial fungal infections. Pediatrics in review/American Academy of Pediatrics, 33(4):e22-37.

Nistal Nuño B, Del Pozo Losada J. (2005) Dermatofitosis o Tiñas. Guias Clinicas.

Restrepo M A, Díaz C F, Estrada M S, Franco R L, Jaramillo A J, Maestre B A, (2007), Fundamentos básicos de Medicina. Microbiología de las infecciones humanas Corporación para Investigaciones Biológicas (Colombia) 914p[Links].

Saura-Calixto F \& Goñi I. (2005) «Fibra dietética y antioxidantes en la dieta española y en alimentos funcionales» Capítulo en el libro «Alimentos funcionales» Fundación Española para la Ciencia y la Tecnología, Madrid; (1 de Mayo do 2005), Tiña, Tinea. Dermatomicosis. Center of Food Security and Public Health, Istitute for international Cooperation in Animal Biologics. (2007) Café y Salud, Radicales Libres y Antioxidantes, Federacioncafe. 